\title{
Aprendizagem Significativa no Ensino de Engenharia
}

Prof. Ms. Anna Cristina Barbosa Dias de Carvalho

Escola de Engenharia de São Carlos - Universidade de São Paulo - Laboratório de Simulação - NUMA

Av. Dr. Carlos Botelho, 1465 Vila Pureza CEP. 13560-250 São Carlos - SP

Tel. (55) 016-2739432 _ FAX (55) 016-2739402 e-mail: abarbosa@sc.usp.br

Prof. Dr. Arthur José Vieira Porto

Escola de Engenharia de São Carlos - Universidade de São Paulo - Laboratório de Simulação - NUMA

Av. Dr. Carlos Botelho, 1465 Vila Pureza CEP. 13560-250 São Carlos - SP

Tel. (55) 016-2739432 - FAX (55) 016-2739402 e-mail: ajvporto@sc.usp.br

Prof. Dr. Renato Vairo Belhot

Escola de Engenharia de São Carlos - Universidade de São Paulo - Área de Produção - Lab. De Multimídia

Av. Dr. Carlos Botelho, 1465 Vila Pureza CEP. 13560-250 São Carlos - SP

Tel. (55) 016-273-9378 - FAX (55) 016-2739402 e-mail: rvbelhot@prod.eesc.sc.usp.br

Esse trabalho tem por objetivo mostrar as teorias da aprendizagem e em especial a utilização da teoria da Aprendizagem Significativa no ensino de Engenharia. É apresentado o conceito de mapa conceptual, que ajudará o professor a planejar suas aulas e também podem ser utilizados pelos alunos no auxílio da ancoragem de conhecimento e a consolidação do conhecimento.

Palavras-Chave: Ensino em Engenharia, Teorias då A.prendizagem, Aprendizagem Significativa

That work has the objective to show the theories of learning and especially the use of the theory of the Significant Learning in teaching of Engineering. The idea of conceptual map is presented, which will help the teacher to plan his classes and it can also be used by the students in the aid of the knowledge anchorage and the consolidation of their knowledge.

Keywords: Teaching in Engineering, Theories of the Learning, Significant Learning

\section{Introdução}

A Engenharia é uma área do conhecimento desenvolvida pela necessidade que o homem teve de aumentar sua capacidade de produção $e$ consequentemente suprir suas necessidades de conforto $e$ bem estar. Ela surgiu, mais formalmente, durante a Revolução Industrial. Época em que surgiram as máquinas capazes de produzir um volume maior, com maior velocidade, diversidade de produtos e com maior precisão. As fábricas passaram a se preocupar com surgimento de novos produtos e volume para aumentar seus lucros. Surgiram, então, técnicas de controle e acompanhamento do processo produtivo. Surgiram várias especialidades de engenharia e cursos especializados na formação da mão-de-obra para atender as necessidades das indústrias e da população, com o desenvolvimento de novos produtos, novas máquinas, novos materiais, novas técnicas de controle.

Esse período é conhecido como a $2^{a}$ onda de desenvolvimento vivida pelo homem, segundo Tofler
(1980). Para ele, o homem começou com a agricultura, passou pela Revolução Industrial e hoje está na era da informação, ou a $3^{a}$ onda.

Essa nova onda ou era que estamos vivendo é caracterizada pela rapidez na busca e aplicação da informação. É mais eficaz quem consegue desenvolver ou aprender mais rápido os conhecimentos. Essa mudança de comportamento não é surpresa, pois o homem é um ser curioso e não se conforma com o que desenvolve, quer sempre conhecer e buscar novos conhecimentos. A Engenharia vive uma época, também, de mudanças intensas. As técnicas utilizadas mudam com uma velocidade assustadora. As necessidades de produtos novos, as questões ambientais, a preocupação com o crescimento econômico, a visão da contribuição na sociedade e o conhecimento do contexto mundial, hoje são exigências implícitas na formação do profissional que atuará na sociedade.

Desta forma, as Escolas de Engenharia precisam ensinar a seus alunos mais que conceitos e fórmulas. Eles 
precisam de preparo para enfrentar as mudanças sem surpresas. Eles precisam aprender a aprender. Os alunos devem estar preparados para buscar novos conhecimentos, identificar o que é importante e aplicar adequadamente, obtendo resultados diferenciadores.

A formação do Engenheiro não pode ser feita somente de fórmulas e conceitos. Ele precisa estar preparado para tomar decisões, saber buscar informações e saber aplicá-las, possuir uma visão sistêmica para melhor analisar situaçōes novas, ou seja, o aluno precisa aprender a aprender.

A engenharia é uma área do conhecimento que necessita passar por mudanças no processo de ensinol

aprendizagem. É necessário associar as ferramentas já conhecidas em pedagogia para facilitar a construção do conhecimento, tornando a aprendizagem um ato que tenha significado para os alunos.

O aluno precisa perceber, desde o início do seu curso, que todos os conceitos que está adquirindo fazem parte de um conteúdo maior. O conjunto desses conceitos será necessário para sua formação, não só profissional, mas humanista

Uma relação mais próxima entre professor e aluno trará contribuição para o crescimento emocional e moral do aluno. A troca de experiências valorizará o aluno $e$ incentivará o professor a tornar-se educador, pois ele saberá que suas experiências estarão sendo passadas e aplicadas de forma eficiente através de seus alunos.

A proposta desse trabalho é apresentar teorias, técnicas e conceitos conhecidos na Pedagogia, que poderiam estar sendo utilizados no Ensino de Engenharia ajudando os alunos a obterem a qualificação necessária.

Serão apresentadas as principais teorias da aprendizagem, a relação dessas teorias com o ciclo da aprendizagem, a teoria da aprendizagem significativa que é uma parte específica de uma das teorias da aprendizagem, os mapas conceituais que são técnicas que auxiliam o professor no preparo das aulas e na aplicação de conceitos em sala de aula junto com os alunos.

\section{Teorias da Aprendizagem}

As teorias da aprendizagem são as referências básicas quando se deseja melhorar o processo de ensinol aprendizagem. Através dessas teorias torna-se mais fácil entender porque alguns alunos aprendem e outros não; porque alguns professores obtêm mais sucesso no ensinar do que outros; porque algumas matérias são mais aplicadas do que outras.

Segundo Bigge (1971), as teorias da aprendizagem são uma área da psicologia que estuda o processo de aprender. São várias as teorias da aprendizagem, como: Gestalt, Behaviorismo, Construtivismo e Aprendizagem Significativa (uma das teorias decorrentes do Construtivismo) Que são apresentadas a seguir:

Para os Behavioristas ou teóricos do condicionamento, a aprendizagem é uma mudança no comportamento. Ela ocorre através de estímulos e respostas, que se relacionam obedecendo a princípios mecanicistas. Logo, a aprendizagem envolve a formação de algum tipo de relação entre séries de estímulos e de respostas. Os Estímulos - as causas da aprendizagem - são agentes ambientais que atuam sobre o organismo, fazendo-o emitir uma resposta ou aumentando a probabilidade de uma resposta de certa classe ou tipo. As respostas efeitos - são reações físicas do organismo a uma estimulação interna ou externa. (Bigge,1971)

Para os neobehavioristas a análise do processo estímuloresposta oferece um perfil da origem desse estímuloresposta. Esse perfil mostra ao educador como é formada a estrutura cognitiva do indivíduo. Um outro ponto importante a ser estudado é o que provoca esse estímuloresposta no indivíduo. Esses fatos são importantes, pois ajudam o educador a elaborar atividades que estimulem a aprendizagem. A aprendizagem para os neobehavioristas ocorre quando o indivíduo como um todo é envolvido no processo. $O$ indivíduo precisa ter a percepção de início e fim do que está sendo analisado ou estudado, o processo iniciado pode ter continuidade através dos conceitos adquiridos, porém tudo que é incorporado a estrutura cognitiva do indivíduo precisa fazer parte das relações deste com o meio em que se relaciona.( Lima, 1999)

Para a teoria Cognitiva ou Gestalt a aprendizagem é um processo através do qual uma pessoa adquire novos insights, estruturas cognitivas ou mudança em antigas estruturas. A aprendizagem ocorre quando o individuo busca em seus conhecimentos antigos suportes para aprender novos conhecimentos que passam gerar mudanças na estrutura cognitiva existente ou desenvolver novas estruturas. Por exemplo, ensinar a tabuada de 9, fazendo os alunos buscarem seus 
conhecimentos seus conhecimentos nas tabuadas de outros números como: 2, 3, 4, 5, 6, 7 e 8 e

consequentemente desmistificando a idéia do difícil. $O$ indivíduo é um todo e todas as suas relações com o sistema em que vive são importantes no processo de aprendizagem.( Lima, 1999)

Piaget utilizou as duas teorias anteriores e desenvolveu estudos sobre o conhecimento através da Epistemogia Genética ou o Construtivismo, como mostra a figura 1.(Franco, 1997).

A teoria de Piaget mostra que a aprendizagem ocorre quando a relação entre o indivíduo e o seu meio de relações está em plena interação. Alguns pontos resumem a teoria de Piaget, segundo Lima. São eles:

1. $O$ indivíduo precisa expressar o que sente livremente, pois através do falar; suas idéias são consolidadas;

2. $O$ individuo precisa participar do processo de transformação. À medida que ele tenta transformar $o$ meio para satisfazer uma necessidade (assimilação), ele se depara com resistências que o obrigam a um esforço de adaptação e, portanto, ocorre a aprendizagem;

3. $O$ individuo não precisa receber respostas prontas. Através dos seus erros e acertos, do expressar o que pensa, tomando consciência do meio em que vive, ele desenvolve um ciclo de aprender a aprender;

4. $O$ individuo aprende mais quando não corre risco de ser discriminado ou de perder algo. Dinâmicas de grupo, jogos de empresa, simulação e realidade virtual são algumas ferramentas que auxiliam o indivíduo a aprender brincando;

5. O indivíduo, normalmente, procura novas situações. É curioso por natureza e busca sempre o novo;

6. $O$ indivíduo precisa se sentir seguro e aceito para desenvolver atitudes e conviver com situações diferentes, sabendo lidar com as mudanças.

Segundo Piaget, esse processo só ocorre quando a capacidade do indivíduo é desenvolvida para conhecer algo ou descobrir algo. Isto ocorre através da interação entre o indivíduo e o objeto gerador de conhecimento. Essa relação é chamada de Construtivismo (Franco, 1997).

Para o Construtivismo uma das principais preocupações é encarar o indivíduo como alguém que possui uma história. Esse conhecimento adquirido ao longo de sua história o auxilia no processo de aprendizagem de novos conhecimentos ou de novos conceitos, ou seja, ensinar não é um ato realizado apenas para que o aluno adquira conhecimentos específicos, mas para que ele cresça integralmente. Surgem, então, algumas questões: como alguém aprende? $O$ que faz uma pessoa adquirir novos conhecimentos?

Para a Teoria de Ausubel, o ponto mais importante no processo de aprendizagem são os conhecimentos adquiridos anteriormente, ou seja, aqueles adquiridos ao longo de sua vida, pois serão ancoras para novos

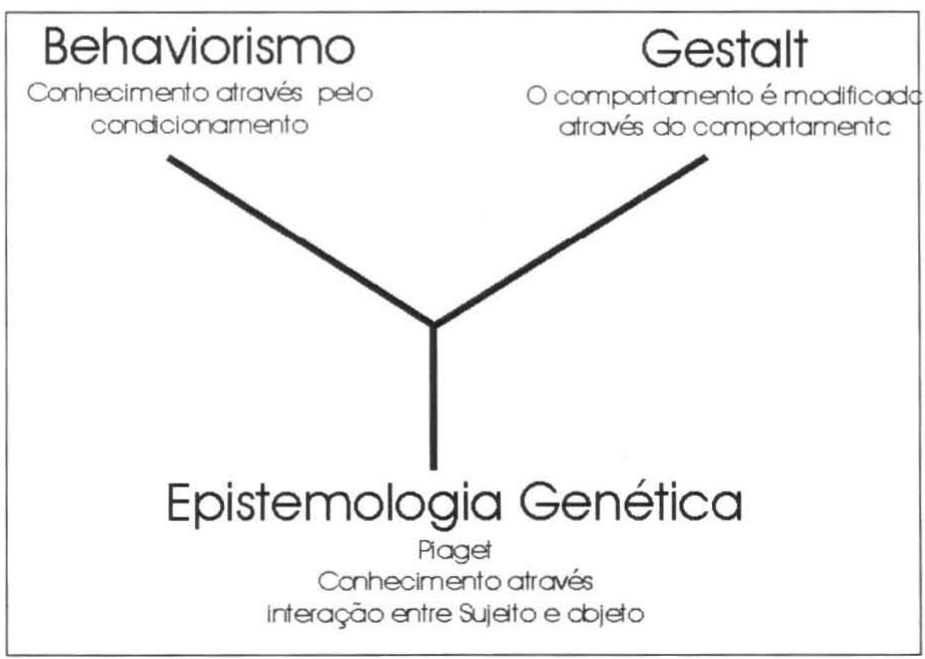

Figura 1. Teoria construtivista

Fonte: Construtivismo e Educação (Franco.1997) 
conhecimentos e idéias, a esse ciclo chamamos de aprendizagem significativa.( Moreira, 1992)

A aprendizagem significativa é um processo pelo qual uma nova informação se relaciona com um aspecto relevante da estrutura de conhecimento do indivíduo.

Qual a importância desse fato para um estudante de Engenharia ou para um professor universitário?

Para o professor, são informações necessárias para que se inicie o processo de aprendizagem: saber quais as motivações que movem seu aluno, o que ele conhece sobre o assunto, como associar assuntos anteriormente estudados com os novos conhecimentos, o que aquilo representa no dia a dia do aluno, como ele poderá aplicar aqueles conhecimentos na sua vida. O professor precisa considerar que o aluno é um indivíduo com conhecimentos, motivações, anseios, dificuldades, medos e aspirações.

$\dot{E}$ o relacionamento entre o que o professor, o aluno $e$ o assunto que possibilita um ambiente propicio para o aprendizado. Como foi visto anteriormente, o indivíduo precisa expressar seus anseios para que o professor possa entender qual a estrutura cognitiva que o indivíduo desenvolveu e como pode ser modificada.

$O$ professor conseguirá desafiar seus alunos a construir novos conhecimentos e fazer uma rede de informações consistente, se procurar entender aquilo que é significativo para eles. O professor passa a ser o mediador das relações existentes entre o aluno e o conteúdo. Essa mediação é necessária para que o aluno seja orientado pelos caminhos que aprendizagem é desenvolvida.

Nas teorias apresentadas pode-se observar que, em todas elas, a necessidade de um ambiente libre para que aluno $e$ professor possam ter sinergia para compartilhar seus conhecimentos.

No ensino de engenharia é importante o contato entre o professor e o aluno, pois muitas vezes o professor possui além do conhecimento teórico, o conhecimento prático do assunto e a maturidade profissional que ajuda o aluno a se sentir mais seguro para aprender e diminuir seus medos em relação a sua capacidade de adquirir o conhecimento

As teorias citadas contribuíram para o desenvolvimento da teoria Construtivista, que tem como finalidade principal a formação do conhecimento ao longo do processo de aprendizagem. Através da teoria construtivista, surge a teoria da aprendizagem significativa, que aplica conceitos construtivistas na formação do conhecimento.

Para entender melhor como funciona a aprendizagem é necessário conhecer como é processado as informações adquiridas pelo indivíduo. O Ciclo da aprendizagem ajuda a entender melhor como o processo de aprendizagem ocorre.

\section{Ciclos da Aprendizagem}

Existem muitas dúvidas sobre:

como ocorre a aprendizagem?

Como tornar uma aula motivadora?

Por que nem todos os alunos se interessam por determinado assunto?

Por que alguns alunos aprendem e outros não?

O conhecimento de técnicas pedagógicas adequadas facilita o desenvolvimento do aluno e o planejamento do professor, o qual deve planejar os recursos necessários para atingir os objetivos desejados eficazmente.

O ciclo da aprendizagem é uma ferramenta importante para que o professor entenda como a aprendizagem está sendo realizada e como o aprendizado pode ser mediado adequadamente.

Conhecer como a aprendizagem acontece permite ao professor entender quando e de que maneira deve aplicar determinado tipo de trabalho ou tecnologia.

Para entender como a aprendizagem ocorre serão apresentados três tipos de ciclos de aprendizagem utilizados em pedagogia:

- Ciclo de Kolb;

- Ciclo de Ginter e White;

- Ciclo Construtivista.

\subsection{Ciclo de Kolb}

O ciclo de Kolb, ilustrado na figura 2, se inicia quando indivíduo é submetido a uma experiência no mundo real conhecida como experiência concreta. $O$ indivíduo analisa o fenômeno e faz uma reflexão sobre o fato, passando para 
a etapa seguinte do ciclo denominada observação reflexiva. Com a finalidade de solidificar conceitos, que the permitam enfrentar situações semelhantes no futuro com mais eficácia, o indivíduo abstrai o conceito passando a generalização das idéias que pode ser denominada de conceituação abstrata. Esses conceitos em formas de idéias serão transformados em ações, que serão testados $\mathrm{em}$ situações reais. Essa é fase conhecida como experimentação ativa, e nela o indivíduo analisa o grau de significância que aquele fato generalizado teve, e se for significativo passará a fazer parte do seu conhecimento, concretizando a aprendizagem.

\subsection{Ciclo de Ginter e White}

No ciclo de Ginter e White, mostrado na figura 3, a aprendizagem social é a principal idéia desenvolvida. Segunda esse ciclo, o indivíduo aprende através da observação do comportamento de outros indivíduos inseridos no mesmo contexto social. Observando as conseqüências boas ou más de ações de outros indivíduos, o observador tende a copiar, ou não, essas ações, apoiando parte do seu comportamento na experiência adquirida por essa observação, mas vivenciada por outros.

Quando o indivíduo aprende um novo comportamento que transforma as atitudes atuais, essa modificação também altera o ambiente em que ele se encontra.

A aprendizagem é então uma desencadeadora de mudanças que, uma vez iniciadas, tendem a tornarem-se permanentes $e$ ininterruptas. Esse é um dos motivos que leva empresas e executivos a iniciarem programas de treinamento.

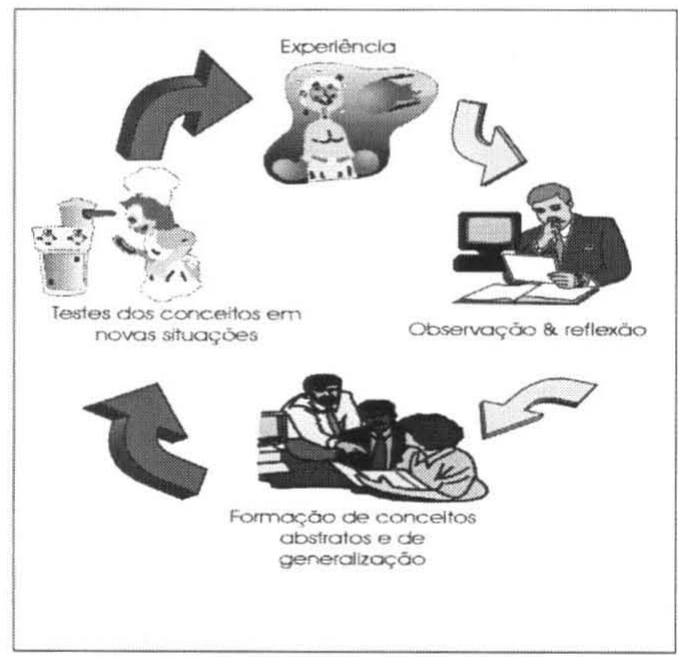

Figura 2. o ciclo de Kolb

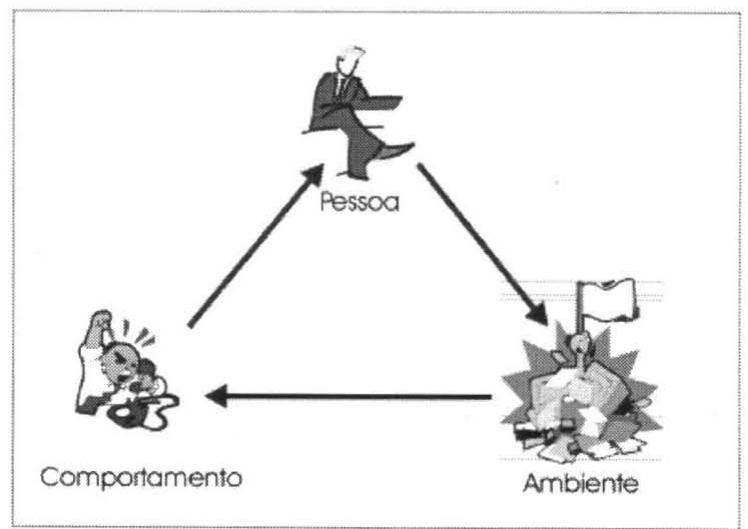

Figura 3. Ciclo de aprendizagem de Ginter e White 


\subsection{Ciclo da aprendizagem na visão Construtivista}

Segundo Santos apud Gramigna (1994), a aprendizagem é um processo que dura toda a vida, ou seja, ele se apresenta como um ciclo no qual um individuo motivado e frente a um desafio consegue resolver uma situação-problema atingindo sua meta $e$ modificando de forma duradoura sua conduta ou comportamento. Neste processo para que a aprendizagem ocorra é necessário que o indivíduo tenha passado por todas as fases do ciclo da aprendizagem. Segundo a visão construtivista o ciclo apresentado na figura 4, mostra as etapas que deverão ser vivenciadas pelo indivíduo em processo de aprendizagem. São elas:

\section{$1^{a}$ etapa - Contextualizar e Justificar}

Nessa etapa são apresentados, ao indivíduo, os conceitos a serem estudados, o porquê de estuda-los, contextualizando-os no meio em que o indivíduo vive. São apresentados os problemas que estão associados a eles e a relevância na resolução dos mesmos. $O$ indivíduo é desafiado ou motivado a entender a importância dos conceitos que serão estudados na etapa seguinte. $2^{\text {a }}$ etapa - Conceitualizar

Nessa etapa são passados todos os conceitos relacionados com o assunto. Essa é a fase na qual se valoriza a lógica, as deduções e as idéias. $O$ indivíduo entra em contato com conceitos novos, mas que estäo relacionados com outros conceitos adquiridos anteriormente.

\section{$3^{\text {a }}$ etapa - Resolver e testar}

Nessa etapa os conceitos apresentados anteriormente são consolidados através de exercícios práticos, aplicações de problemas relacionados. São estimulados o desenvolvimento das habilidades e a criatividade do indivíduo;

\section{$4^{a}$ etapa - Novas Situações}

Nessa etapa o indivíduo aplica os conceitos consolidados em situações reais, desenvolvendo segurança na tomada de decisão, experiência, dando ao indivíduo condições de checar se a aplicação dos conceitos adquiridos na $1^{a}$ etapa.

Esse ciclo explica todas as etapas que passa um indivíduo para aprender. Devido a sua abrangencia e aplicação na teoria da aprendizagem significativa, foi utilizado para

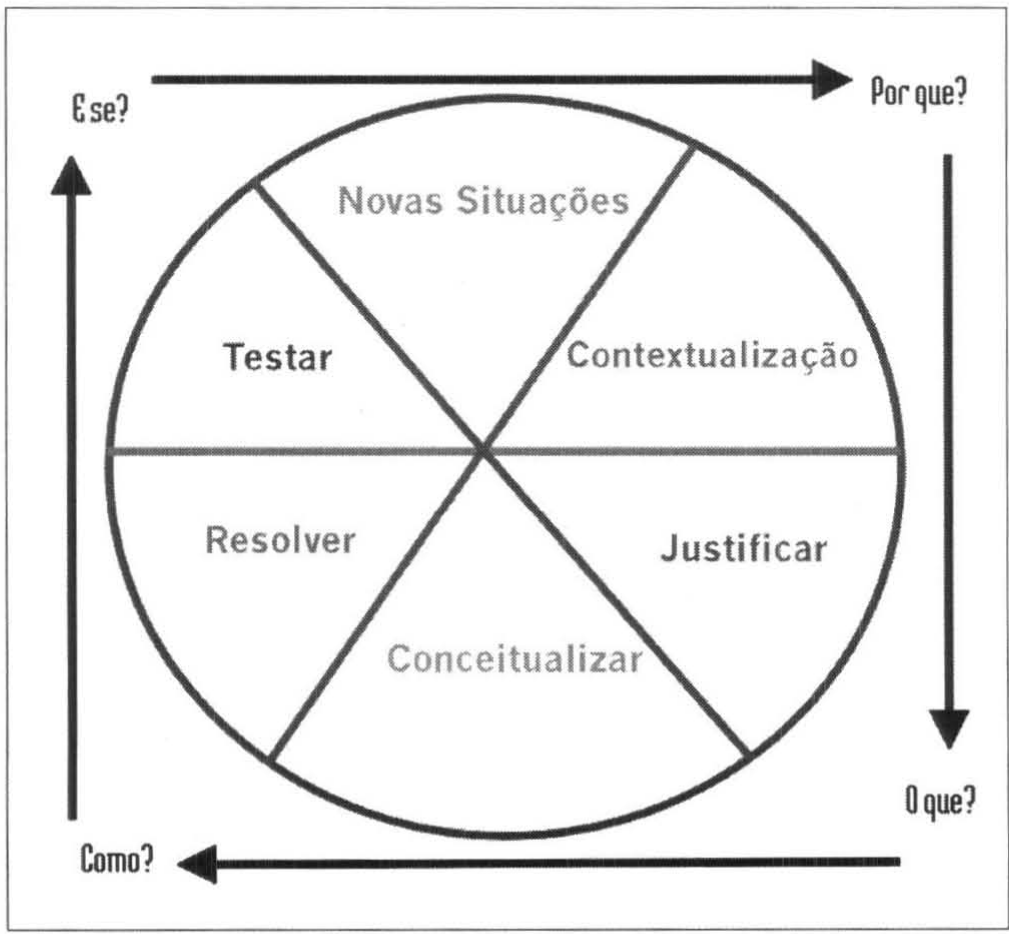

Figura 4. Ciclo da aprendizagem segundo a visão construtivista . Belhot. (1997) 
análise e aplicação no ensino de Engenharia.

A aprendizagem ocorre quando o indivíduo consegue entender os conceitos, associá-los a outros conceitos $e$ aplicá-los. A vivência completa do ciclo construtivista oferece $95 \%$ de absorção do aprendizado. (Belhot,1997)

É importante que o professor conheça o ciclo da aprendizagem, pois é através dele que o planejamento do ensino e das atividades serão facilitados.

Para iniciar o ciclo da aprendizagem, o professor precisa considerar que o aluno tem conhecimentos anteriores, $e$ esses conhecimentos precisam ser identificados para que os novos conceitos possam ser ancorados neles. Esse é o princípio básico da aprendizagem significativa, que será apresentado a seguir.

\section{Aprendizagem Significativa}

A Aprendizagem Significativa ocorre quando a nova informação ancora-se em conceitos relevantes preexistentes na estrutura cognitiva de quem aprende. Ausubel vê o armazenamento de informações no cérebro humano como sendo altamente organizado, formando uma hierarquia conceitual na qual elementos mais específicos de conhecimento são ligados a conceitos mais gerais. Estrutura cognitiva significa, portanto, uma estrutura hierárquica de conceitos que são abstrações da experiência do indivíduo. (Moreira, 1982).

A principal preocupação da teoria de Ausubel é que, os conceitos novos se relacionem ao que o indivíduo já sabe ou algum aspecto relevante da sua estrutura de conhecimento. Para esse fato ocorrer é necessário que:

a) o material a ser aprendido seja potencialmente significativo para o indivíduo, relacionáveis a sua estrutura de conhecimento de forma significativa;

b) o indivíduo manifesta uma disposição de relacionar o novo material a sua estrutura cognitiva.

Nos pontos levantados acima, pode-se observar a necessidade de: adequação do material a ser utilizado pelo professor e segundo um nivel de motivação do individuo que vai aprender, ou seja, sem o envolvimento do aluno e do professor é difícil ocorrer a aprendizagem.

Aprendizagem Significativa depende da relação professor/aluno. O professor deve apresentar um material que tenha coerência com os conceitos adquiridos anteriormente pelo indivíduo, não só conceitos técnicos, mas conhecimentos gerais, desafiando o indivíduo a buscar mais e desenvolver novas fontes para sua estrutura cognitiva. Por outro lado, o indivíduo precisa estar disposto a ser desafiado e a buscar os novos horizontes de conhecimentos.

Essa relação entre professor/aluno facilita a satisfação de ambos, pois a aprendizagem ocorrerá naturalmente. Ambos se beneficiam nesse processo, pois o indivíduo aprende de forma eficaz e o professor atinge seu objetivo, que é orientar o indivíduo no aprendizado de novos conceitos ajudando-o a construir ambições e novos conceitos.

A teoria básica da Aprendizagem Significativa é simples e fácil de ser aplicada, porém exige uma preparação da hierarquia de conceitos a serem passados pelo professor e o conhecimento do ciclo da aprendizagem para facilitar o uso de ferramentas auxiliares adequadamente.

\section{Ferramentas da Aprendizagem Significativa}

Entende-se por hierarquia de conceitos, a seqüência de conceitos e a identificação dos conceitos gerais e os conceitos complementares. Essa hierarquia ajuda o indivíduo a entender a seqüência lógica do assunto, facilitando a ancoragem de conceitos anteriores.

Para conhecer a hierarquia de conceitos a ser compartilhada com os alunos, o professor precisa fazer um planejamento adequado. Uma ferramenta utilizada na teoria da aprendizagem significativa é o mapa conceitual.

Os mapas conceituais são modelos identificação de conteúdos que auxiliam o professor e o aluno, a entender quais os conceitos gerais, quais os conceitos intermediários e onde aplicar esses conceitos.

Segundo Gowin e Novak (1999) os mapas conceituais são proposições onde dois ou mais termos conceituais estão ligados por palavras de modo a formar uma unidade semântica. Eles são utilizados para tornar claro, para alunos e professores, o número de idéias que devem ser focadas para uma aprendizagem específica. Os mapas conceituais auxiliam o professor a definir o que é importante no conteúdo do curso que está sendo planejado, além de ajudá-lo na escolha dos exemplos e do tipo de tecnologia adequada para aquela etapa do ciclo. 


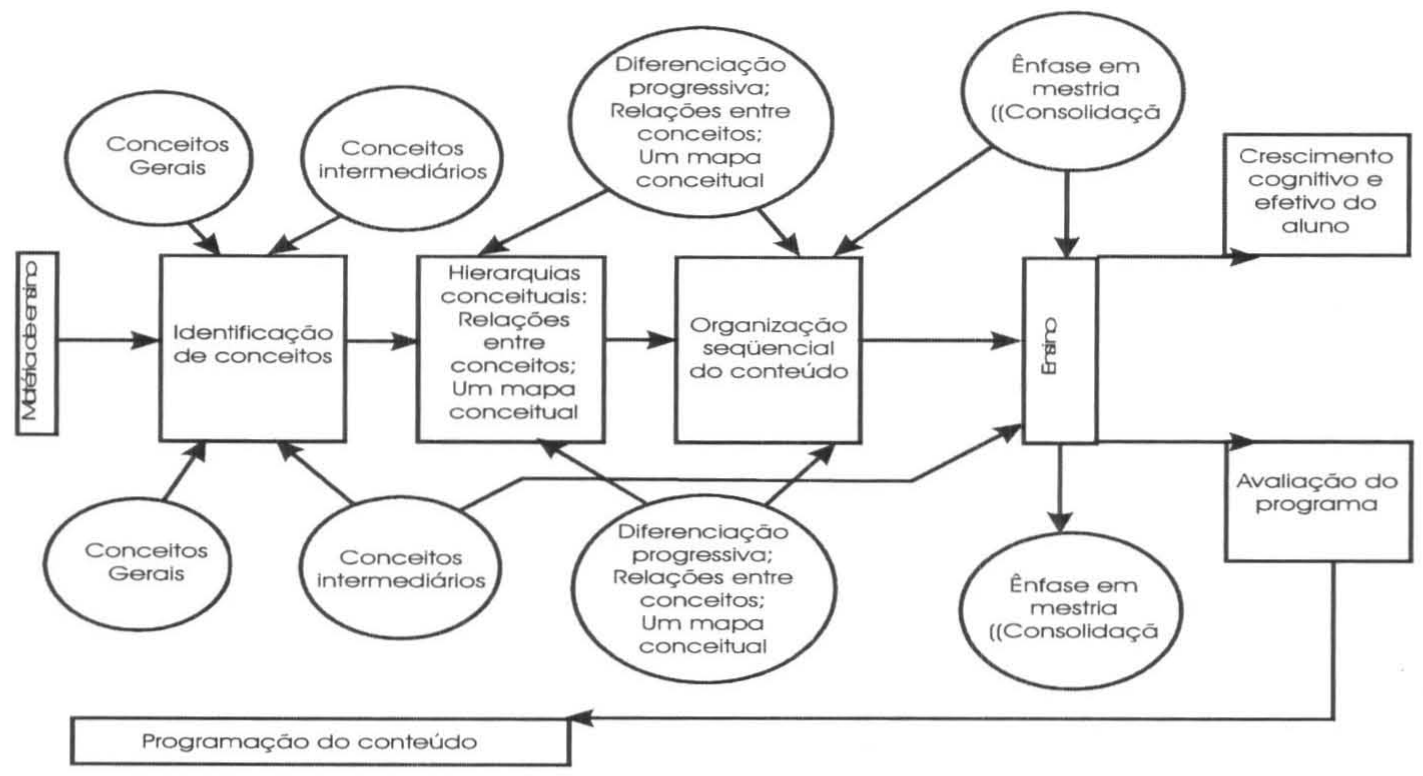

Figura 5. Modelo para planejamento da instrução, segundo Ausubel. Fonte: Moreira,1982

O aluno por sua vez, após cada apresentação de conteúdo, será capaz de identificar exatamente qual o objetivo da aula e o que aquele conteúdo acrescentou no seu aprendizado. Os mapas conceituais auxiliam o professor a ver o conteúdo como um todo e quais as etapas deverão ser melhor desenvolvidas, quais as idéias que devem ser apresentadas para os alunos identificando os conceitos sobre o assunto e os associando a novos conceitos.

A figura 6 mostra um exemplo de aplicação, através da utilização de um mapa conceitual para definir a seqüência de conceitos importantes para ensinar sobre força.

A montagem do mapa conceitual é muito importante para que o professor entenda a seqüência correta de conceitos que precisam ser utilizados para o bom entendimento do todo. Essa montagem deve ser realizada durante a fase de planejamento de aula ou planejamento do curso. O professor escolhe o conteúdo programático através da seqüência de conceitos gerais, em seguida identifica que conceitos são decorrentes dos conceitos gerais, fazendo a hierarquia e a relação entre os conceitos intermediários. Identificados todos os conceitos (gerais e intermediários) o professor escolhe que tipos de ferramentas de ensino estão disponíveis e como podem ser aplicadas para consolidar os conceitos que serão apresentados. Essas ferramentas facilitam o processo de ensino aprendizagem. Em Engenharia podem ser utilizadas recursos como: simulação, jogos de empresa, dinâmica de grupo, estudo de caso, realidade virtual.

Ao final da fase de consolidação o professor precisa avaliar se realmente o aluno aprendeu os conceitos apresentados. Essa avaliação pode ser feita também com os recursos citados acima ou através de provas ou problemas no mundo real.

Essas etapas orientada pelo mapa conceitual podem ser associadas ao ciclo da aprendizagem. Onde o indivíduo conhece conceitos novos, contextualiza esses conceitos, solidifica-os e os aplica em situações da vida real. Todos esses conhecimentos são utilizados durante a fase de planejamento do professor.

Em sala de aula, a principal preocupação é com a utilização dos recursos que facilitem a passagem da estrutura conceitual da disciplina para a estrutura cognitiva do aluno, tornando o material significativo.

$O$ professor pode utilizar o mapa conceitual montado no planejamento para ser executado em sala de aula com o aluno. Os conceitos vão surgindo e sendo associados com outros conhecimentos já adquiridos pelo aluno. Ao final da montagem do mapa, o aluno consegue aprender.

É importante lembrar que o processo de aprender necessita da motivação do aluno e do envolvimento do professor com os conteúdos a serem apresentados e com o aluno. 


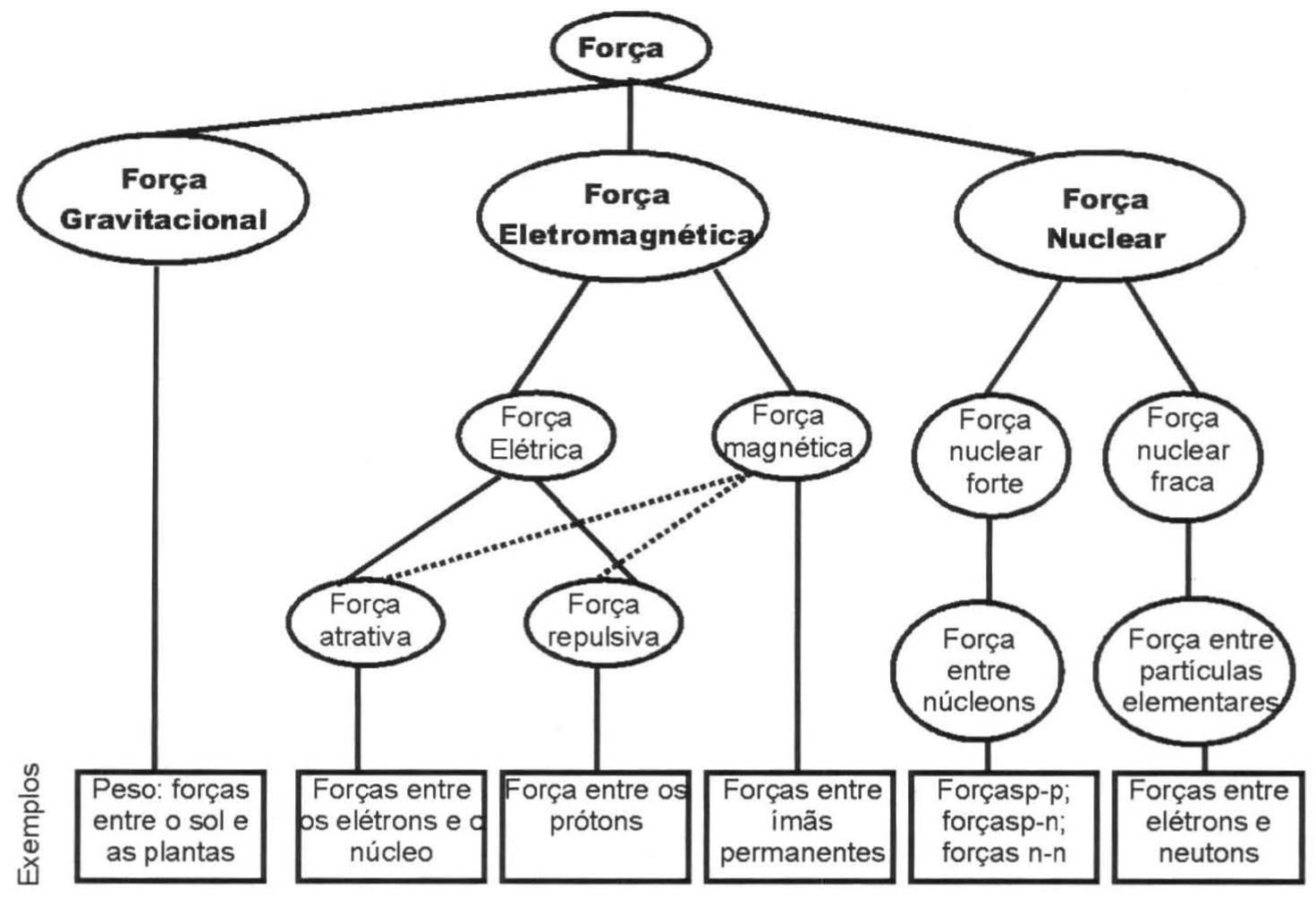

Figura 6. Exemplo de mapa conceitual sobre o conceito de força. Fonte: Moreira, 1982

$O$ uso dos recursos para consolidação do conhecimento será apresentado em um outro artigo, pois não é o objetivo do presente trabalho.

Em Engenharia, é extremamente importante que o aluno possa vivenciar situações reais, onde ele possa tomar decisões sobre assuntos importantes, em ambiente controlado. Com o uso dos mapas conceituais e a teoria da aprendizagem significativa não existe consolidação do conhecimento sem a experiência na vida real. Esses são recursos que auxiliam o professor a não perder seus objetivos e ajusta-los de acordo com o desenvolvimento do aluno, tornando o ensino eficaz.

\section{Considerações Finais}

Foi apresentado durante esse trabalho a importância da aplicação da teoria da Aprendizagem Significativa no ensino de Engenharia.

Sem um mudança no processo de ensinol aprendizagem, os alunos continuarão a sair de seus cursos com dificuldades para se adaptarem as mudanças exigidas pelo mercado.
A Engenharia é uma área importante no desenvolvimento econômico e social de um país, por essa razão precisa passar por mudanças e aprimorar a forma como são formados seus profissionais.

Esse não é um estudo acabado. $O$ objetivo do presente trabalho é apenas despertar os professores $e$ universidades para técnicas e teorias já existentes adaptadas ao ensino de Engenharia.

Posteriormente, é necessário estudar como aplicar ferramentas tecnológicas de forma eficiente.

\section{Bibliografia}

BELHOT, R.V. Reflexões e propostas sobre o "Ensinar engenharia" para o século XXI. Tese (Livre Docência), EESC, USP, São Carlos, 1997;

BETHLEM, Agrícola; Estratégica Empresarial: conceitos, processo e administração estratégica, Ed. Atlas S.A, São Paulo, 1998;

BIGGE, Moris, L.; Teorias da aprendizagem para professores, ed. EPU Ltda, São Paulo, 1977;

-BOMFIM, David; Pedagogia no Treinamento: Correntes 
Pedagógicas no Treinamento Empresarial, Ed.

Qualitymark, Rio de Janeiro, 1995;

- COLL, César; MARTÍN, Elena; MAURI, Tereza et all; O construtivismo na sala de aula, Ed. Ática, $5^{a}$ Edição, São Paulo, 1998;

- FRANCO, Sérgio Roberto Kieling; O construtivismo e a educação, Editora Mediação, $6^{a}$ edição, Porto Alegre, 1997;

- GRAMIGNA, Maria Rita; Jogos de Empresa, MAKRON Books Editora Ltda, São Paulo, 1994;

- GRAMIGNA, Maria Rita; Jogos de empresa e Técnicas vivenciais, MAKRON Books Editora Ltda, São Paulo,1997;

- LIMA, Adriana Flávia Santos de Oliveira. Pré-escola e alfabetização. Vozes, $11^{a}$ ed., Petrópolis -RJ,1986;

- MOREIRA, Marco A .; MASINI, Elcie F. Salzano; Aprendizagem significativa a teoria de David Ausubel, Ed.Moraes LTDA, São Paulo, 1992;

- NOVAK, Joseph ., GOWIN, D. Bob; Aprender a aprender, Platano edições técnicas, $2^{a}$ edição, Lisboa, 1999;

- PALADINI, Edson Pacheco, Dr. Eng.; Motivação à aprendizagem: A perspectiva humana nos cursos de engenharia, pag.1665 a1678, anais do Cobenge,1997;

- SANTANA, Marcos Jorge A., SANTOS, Dermivan Barbosa dos; Aprender fazendo, pag.2225 a 2234, anais do Cobenge 1997;

- SENGE, Peter M.; A Quinta Disciplina - arte e prática da organização que aprende, Ed.Best Seller, São Paulo, 1998;

- SOUZA, José Geraldo de ; A docência na escola de engenharia: para além da qualidade formal, pag. 1847 a 1855, anais do Cobenge 1997; 